\title{
Induced abortion as an independent risk factor for breast cancer: a comprehensive review and meta-analysis
}

\author{
Joel Brind, Vernon M Chinchilli, Walter B Severs, Joan Summy-Long
}

\begin{abstract}
Study objective - To ascertain, from the published reports to date, whether or not a significantly increased risk of breast cancer is specifically attributable to a history of induced abortion, independent of spontaneous abortion and age at first full term pregnancy (or first live birth); to establish the relative magnitude of such risk increase as may be found, and to ascertain and quantify such risk increases as may pertain to particular subpopulations of women exposed to induced abortion; in particular, nulliparous women and parous women exposed before compared with after the first full term pregnancy.

Included studies - The meta-analysis includes all 28 published reports which include specific data on induced abortion and breast cancer incidence. Since some study data are presented in more than one report, the 28 reports were determined to constitute 23 independent studies. Overall induced abortion odds ratios and odds ratios for the different subpopulations were calculated using an average weighted according to the inverse of the variance. An overall unweighted average was also computed for comparison. No quality criteria were imposed, but a narrative review of all included studies is presented for the reader's use in assessing the quality of individual studies.
\end{abstract}

Excluded studies - All 33 published reports including data on abortion and breast cancer incidence but either pertaining only to spontaneous abortion or to abortion without specification as to whether it was induced or spontaneous. These studies are listed for the reader's information.

Results - The overall odds ratio (for any induced abortion exposure; $n=21$ studies) was $1.3(95 \%$ confidence interval of 1.2 , 1.4). For comparison, the unweighted overall odds ratio was $1.4(1.3,1.6)$. The odds ratio for nulliparous women was 1.3 $(1.0,1.6)$, that for abortion before the first term pregnancy in parous women was 1.5 $(1.2,1.8)$, and that for abortion after the first term pregnancy was $1.3(1.1,1.5)$. Conclusions - The results support the inclusion of induced abortion among significant independent risk factors for breast cancer, regardless of parity or timing of abortion relative to the first term pregnancy. Although the increase in risk was relatively low, the high incidence of both breast cancer and induced abortion suggest a substantial impact of thousands of excess cases per year currently, and a potentially much greater impact in the next century, as the first cohort of women exposed to legal induced abortion continues to age.

( $\mathcal{A}$ Epidemiol Community Health 1996;50:481-496)

Epidemiological evidence of a positive association between induced abortion and the incidence of breast cancer was first presented by Segi et $\mathrm{al}^{1}$ in 1957 based on cases diagnosed between 1948 and 1952. Experimental evidence of a causal association between induced abortion and breast cancer in rodents was presented by Russo and Russo ${ }^{2}$ in 1980 . Yet, despite the alarmingly high incidence of both breast cancer and induced abortion, the last four decades have produced neither consensus of opinion within the medical research community nor a sense of urgency to arrive at one. Although a few dozen studies have appeared worldwide, and many of them support a positive association, the potential of induced abortion as a breast cancer risk factor continues largely to be minimised. For example, the recent study by Daling $e t a l^{\beta}$ which reported a significant, $50 \%$ increase in the overall risk attributable to induced abortion, was published in the fournal of the National Cancer Institute with an accompanying editorial by Rosenberg ${ }^{4}$ which described the results as "far from conclusive". Similarly, in a more recent study of women in Greece, Lipworth et at confirmed the overall findings of Daling et $a l^{\beta}$ but nevertheless concluded: "At this stage, perhaps all that can be definitively stated is that any risk associated with induced abortion is at most statistically marginal". Previous reviews have also not served to clarify this issue. The New England fournal of Medicine's extensive, 1992 review of breast cancer ${ }^{6}$ fails to mention abortion at all, even among potential risk factors. The same is true for the recent breast cancer review ${ }^{7}$ published in The Lancet. Reviewers who have included a discussion of induced abortion as a real or potential risk factor have not been comprehensive, ${ }^{8-12}$ and also often fail (as do many of the original epidemiological studies) to distinguish between induced and spontaneous abortion. ${ }^{89}$ Even when the distinction is made, erroneous citations are common. For example, Harlap ${ }^{11}$ cites studies by Hadjimichael et $a l^{13}$ and Vessey et $a l^{14}$ as examples of studies of 
Table 1 Epidemiological studies on abortion and breast cancer incidence which do not report specific data on induced abortion

\begin{tabular}{|c|c|c|c|c|}
\hline Author(s) & Year & Nation of study population & Overall $O R$ (ever/never) & Significant? (yes/no) \\
\hline Wynder et $a l^{20}$ & 1960 & Japan & 1.64 & No \\
\hline Stewart et al $l^{1}$ & 1966 & Israel (Jewish) & $>1$ & Yes* \\
\hline Valaoras et $a l^{22}$ & 1969 & Greece & 1.22 & Yest \\
\hline Salber et $a l^{23}$ & 1969 & USA (white) & 0.97 & Not \\
\hline Lowe and MacMahon ${ }^{24}$ & 1970 & Wales & 0.89 & Not \\
\hline Yuasa and MacMahon ${ }^{25}$ & 1970 & Japan & 1.25 & Yest \\
\hline Mirra $e t a l^{26}$ & 1971 & Brazil & 1.30 & Not \\
\hline Ravnihar et al ${ }^{7}$ & 1971 & Slovenia & 0.94 & Not \\
\hline Lin $e t a 2^{8}$ & 1971 & Taiwan & 1.30 & Not \\
\hline Paymaster and Gangadharan ${ }^{29}$ & 1972 & India & 0.74 & Yes \\
\hline Stavraky and Emmons ${ }^{30}$ & 1974 & Canada & 1.59 & No \\
\hline Abeatici et $a l^{1}$ & 1975 & Italy & 0.36 & No \\
\hline Herity et $a^{\beta^{2}}$ & 1975 & Ireland & Data not shown & No \\
\hline Soini ${ }^{33}$ & 1977 & Finland & 1.6 & Yes \\
\hline Choi et al ${ }^{34}$ & 1978 & Canada & $>1$ & Yesł \\
\hline Toti et $a l^{35}$ & 1980 & Italy & $<1$ & Noł \\
\hline Paffenbarger et $a l^{\beta 6}$ & 1980 & USA (all races) & 0.81 & Yes \\
\hline Kelsey et $a b^{7}$ & 1981 & USA (all races) & 1.7 & Nos \\
\hline Lubin et $a^{\beta 8}$ & 1982 & Canada & 1.0 & No§ \\
\hline Vessey et $a l^{14}$ & 1982 & England & 0.84 & Noई** \\
\hline Helmrich et $a l^{39}$ & 1983 & $95 \%$ USA & 1.0 & Nott \\
\hline Enachescu and Lemneanu ${ }^{40}$ & 1984 & Romania & 2.45 & Yes** \\
\hline Talamini et al & 1985 & Italy & 0.74 & Nott \\
\hline Levshin and Chepurko ${ }^{19}$ & 1985 & Russia & 1.6 & Yes** \\
\hline Hadjimichael et al ${ }^{13}$ & 1986 & USA & 3.5 & Yes $\delta^{* *} \neq \ddagger$ \\
\hline Kvale et $a l^{42}$ & 1987 & Norway & 0.84 & Noł⿰ \\
\hline Yuan et al $t^{43}$ & 1988 & China (PRC) & 0.89 & No \\
\hline Bernstein $e t a l^{44}$ & 1990 & USA (white) & 1.13 & Nott \\
\hline Sellers et $a t^{45}$ & 1993 & USA ( $99 \%$ white) & 1.2 & No@ł $\int S$ \\
\hline Gandra et $a l^{17}$ & 1993 & Portugal & 0.5 & Yes. \\
\hline Andrieu $e t a l^{46}$ & 1993 & France & 1.0 & Nott \\
\hline Rao et $a l^{47}$ & 1994 & India & 0.8 & \\
\hline Andrieu $e t a l^{48}$ & 1994 & France & $1.4-2.1$ & $\mathrm{No}^{* * *}+\mathrm{t}+$ \\
\hline
\end{tabular}

* Data given in terms of number of pregnancies rather than number of subjects.

†Data shown are as presented in 1995 reanalysis of Michels et al .

$¥$ Data given in form other than odds ratio or relative risk.

$\oint$ Abortions stated to be all or mostly all spontaneous.

** OR given is for abortion before full term pregnancy only.

t† Other paper(s) by same group on same or overlapping study population contain specific data on induced abortion and are included in the present meta-analysis.

if Cohort study.

\#f Cohort study.
$\delta \oint$ Specific data on induced abortion collected but not shown.

*** Two or more abortions only.

t†† Abstract only.

induced abortion, whereas the former dealt exclusively, and the latter almost exclusively, with spontaneous abortion. It is therefore the purpose of the present study to establish whether or not clear trends exist in the epidemiological literature specifically about any overall relationship between induced abortion and breast cancer. Evaluation of relationships within certain subgroups are included where sufficient data have been published. This analysis should prove useful in clarifying directions for future research, and provide a basis for guidelines governing clinical practice. It is also hoped that the present work will eliminate the current confusion regarding spontaneous versus induced abortion vis-a-vis breast cancer risk, and that it will ultimately help women considering elective abortion to make better informed choices.

\section{Methods}

SEARCH METHODS

Published studies were located using the Medline (National Library of Medicine, USA) databases back to the earliest available publication date (1966), using the subject search terms "abortion", "breast" and "cancer", and by searching bibliographies of original studies and review papers. English translations of studies published in Japanese, ${ }^{1516}$ Portuguese, ${ }^{17}$ and Russian $^{1819}$ were professionally provided by contract with the Frank C Farnham Co (Philadelphia, PA, USA).
STUDIES EXCLUDED FROM THE QUANTITATIVE ANALYSIS

Table 1 lists all published studies to date which report on the association between abortion and breast cancer incidence but which do not report specific data on induced abortion. ${ }^{13141719-48}$ In some cases, the distinction between induced and spontaneous abortion was not made during data acquisition, and in others, data were collected separately and combined for analysis. The 1979 study by Levshin and Chepurko ${ }^{19}$ is briefly summarised in English in Remennick's 1990 review, ${ }^{12}$ in which the "slightly increased" risk of breast cancer in women with abortion before first full term pregnancy is ascribed to induced abortion. However, the original study does not distinguish between induced and spontaneous abortion. The studies of Hadjimichael et $a l^{13}$ and Sellers et $a l^{45}$ report data for spontaneous abortion only. In the latter study, the authors collected data on induced abortion, but stated only that, "The reported frequency of induced abortions was low". Vessey et $a l^{14}$ combined data for induced and spontaneous abortion before first full term pregnancy, but induced abortion accounted for "only a handful" of the 113 cases and 127 controls in this category. Bernstein et al $l^{44}$ presented only combined data in terms of "incomplete pregnancy" in their continuation of the study of Pike et al. ${ }^{49}$ In the original study, ${ }^{49}$ which we include in the quantitative metaanalysis, separate data are presented for induced and spontaneous abortion. The reports 
of Helmrich et al, ${ }^{39}$ Talamini $e t a l,{ }^{41}$ and Andrieu et $a l^{46}$ represent studies whose data on induced abortion and breast cancer risk are presented in other reports which are included in the quantitative meta-analysis. Of the 33 studies not reporting specific data on induced abortion, 29 present data in terms of relative risk (RR) or odds ratio (OR), with a range of values from 0.36 to 3.5 (table 1). Of these, five studies report values at or below $0.8,12$ between 0.8 and 1.2 , and 12 report values above 1.2. Thus, the lack of a significant trend is obvious.

\section{DESIGN OF THE META-ANALYSIS}

To date we have located 28 original published reports which describe a total of 23 independent studies which report data specifically on induced abortion and breast cancer. Based on the particular questions most commonly addressed, the meta-analysis summarises the data according to the following categories:

1. Overall breast cancer OR for women with a history of: one or more induced abortions: $(n=$ 21 studies)

2. Breast cancer OR in women with a history of one or more induced abortions before a first full-term pregnancy, who are: either parous or nulliparous: ( $n=7$ studies)

a: nulliparous: ( $n=7$ studies)

b: parous: ( $n=6$ studies)

3. Breast cancer $O R$ in (parous) women with a history of one or more induced abortions only after the first full term pregnancy: $(n=6$ studies)

\section{NARRATIVE REVIEW OF INCLUDED STUDIES}

Since the detailed "epidemiological study on cancer in Japan" was published by Segi et al in 1957, before the basic methods of epidemiological data analysis were standardised by Mantel and Haenszel, ${ }^{50}$ their data were analysed differently from all subsequent studies. This would present no difficulty for inclusion in the meta-analysis if raw data were given in terms of numbers of exposed and unexposed patients and controls. However, Segi et ll $^{1}$ reported their data in terms of numbers of pregnancies of each type - ie, live births, still births, spontaneous abortions, and induced abortions. Thus, the numbers of exposed and unexposed subjects cannot be ascertained, even though the numbers of patients $(n=432)$ and controls $(n=1713)$ are specified. Fortunately, data reported for exposure rates in two other Japanese studies provide a basis for a reasonable estimation of the number of exposed patients in the study of Segi et al. ${ }^{1}$ Published in 1968, the study of Watanabe and Hirayama ${ }^{15}$ presents $R R$ calculations for each number of induced abortions in patients admitted for breast cancer surgery between 1940 and 1942. Thus, the mean numbers of abortions per patient and per control who had had at least one induced abortion are 1.92 and 1.82 , respectively. The second Japanese study that can be used is the 1982 study by Nishiyama ${ }^{16}$ of a patient population admitted from 1970 through 1979, and the mean numbers of induced abortions per patient and control who had had at least one are 1.82 and 1.65 , respectively. The only other study of Japanese women giving data on induced abortion and breast cancer is that of Hirohata $e t a p^{1}$, in which only dichotomous data are given. Since the patients studied by Segi et $a l^{1}$ were hospitalised for breast cancer between 1948 and 1952, the study populations of Watanabe and Hirayama ${ }^{15}$ and Nishiyama ${ }^{16}$ bracket them in time in addition to agreeing closely on the induced abortion exposure rate. Therefore, we have averaged the exposure rates for patients (1.87) and controls (1.74) in these two studies in order to estimate the number of exposed patients $(n=53)$ and controls $(n=$ 86) represented by the numbers of artificially aborted pregnancies given by Segi et al. ${ }^{1}$ These assumptions and calculations make it possible to include the study of Segi et $a l^{1}$ in the metaanalysis under category 1 (table 2), although

Table 2 Odds ratios and 95\% confidence intervals for different categories of exposure to induced abortion in component studies of the meta-analysis

\begin{tabular}{|c|c|c|c|c|c|c|c|}
\hline \multirow[b]{3}{*}{ Ref no } & \multirow[b]{3}{*}{ Year } & \multirow{3}{*}{$\begin{array}{l}\text { Nation of study } \\
\text { population }\end{array}$} & \multicolumn{4}{|c|}{ OR and $95 \%$ confidence interval for exposure category } & \multirow{3}{*}{$\begin{array}{l}\text { Induced abortion } \\
\text { after FFTP only }\end{array}$} \\
\hline & & & \multirow{2}{*}{$\begin{array}{l}\text { Any induced } \\
\text { abortions }\end{array}$} & \multicolumn{3}{|c|}{ Induces abortion before FFTP* } & \\
\hline & & & & Any parity & Nulliparous & Parous & \\
\hline 1 & 1957 & Japan & $2.63+(1.85,3.75)$ & - & - & - & - \\
\hline 15 & 1968 & Japan & $1.51+(0.91,2.53)$ & - & - & - & - \\
\hline 18 & 1978 & Russia & $1.71+(0.80,3.64)$ & - & - & - & - \\
\hline 52 & 1979 & Yugoslavia & $0.50 \dagger(0.33,0.74)$ & - & 一 & - & - \\
\hline 49 & 1981 & USA & - & $2.37(0.85,6.93)$ & - & - & - \\
\hline 16 & 1982 & Japan & $2.52 \dagger(1.99,3.20)$ & - & - & - & - \\
\hline 53 & 1983 & USA & $1.2(0.6,2.3)$ & $2.2(0.7,7.2)$ & $5.5(0.8,36.8)$ & $1.34(0.3,5.6)$ & $0.89(0.4,2.0)$ \\
\hline 54 & 1984 & France & $1.32(0.97,1.77)$ & 一 & - & - & 一 \\
\hline $\begin{array}{l}51 \\
55\end{array}$ & $\begin{array}{l}1985 \\
1988\end{array}$ & $\begin{array}{l}\text { Japan } \\
\text { Denmark }\end{array}$ & $1.52(0.93,2.48)$ & 二 & $\overline{291}+(0.77,162)$ & 二 & 二 \\
\hline 56 & $\begin{array}{l}1988 \\
1988\end{array}$ & $\begin{array}{l}\text { Denmark } \\
\text { USA }\end{array}$ & $1.2(1.0,1.6)$ & $1.1(0.8,1.6)$ & $\begin{array}{l}2.91+(0.77,16.2) \\
1.3(0.8,2.2)\end{array}$ & $\overline{0.9}(0.5,1.4)$ & $\overline{1.4}(1.0,1.9)$ \\
\hline 57 & 1989 & USA & $1.9(1.2,3.0)$ & - - & - & & - \\
\hline 58,59 & 1989,1990 & Sweden, Norway & $0.9(0.5,1.3)$ & $1.09(0.71,1.56)$ & - & $0.82 \dagger(0.44,1.51)$ & $0.58(0.38,0.84)$ \\
\hline $\begin{array}{l}61,63 \\
64\end{array}$ & 1991,1993 & Italy & $0.92(0.80,1.06)$ & - & $0.8(0.4,1.5)$ & - & - \\
\hline $\begin{array}{l}64 \\
65\end{array}$ & $\begin{array}{l}1993 \\
1993\end{array}$ & $\begin{array}{l}\text { USA } \\
\text { USA }\end{array}$ & $\begin{array}{l}1.0(0.7,1.4) \\
3.1(2.0,4.8)\end{array}$ & - & - & - & - \\
\hline 66 & 1994 & USA & $2.44(1.0,6.0)$ & - & - & $\overline{-}$ & - \\
\hline 67 & 1994 & France & $1.1(0.7,1.8)$ & - & - & - & - \\
\hline $\begin{array}{l}3,68 \\
69\end{array}$ & $\begin{array}{l}1994 \\
1995\end{array}$ & $\begin{array}{l}\text { USA } \\
\text { USA }\end{array}$ & $\begin{array}{l}1.36(1.11,1.67) \\
0.99(0.81,1.21)\end{array}$ & $1.5(1.1,2.0)$ & $1.7(1.1,2.6)$ & $1.4(1.0,2.0)$ & $1.5(1.0,2.2)$ \\
\hline 5 & $\begin{array}{l}1995 \\
1995\end{array}$ & Greece & $\begin{array}{l}0.99(0.81,1.21) \\
1.51(1.24,1.84)\end{array}$ & $\overline{1.68}(1.25,2.25)$ & $0.98(0.56,1.73)$ & $2.06(1.45,2.90)$ & $\overline{1.59}(1.24,2.04)$ \\
\hline $\begin{array}{l}70 \\
71\end{array}$ & $\begin{array}{l}1995 \\
1996\end{array}$ & $\begin{array}{l}\text { Netherlands } \\
\text { USA }\end{array}$ & $1.9(1.2,3.1)$ & $1.45(0.76,2.75)$ & $0.9(0.4,2.3)$ & $2.6(1.0,6.8)$ & $1.7(0.9,3.1)$ \\
\hline & 1996 & USA & $1.23(1.00,1.51)$ & - & 一 & - & \\
\hline
\end{tabular}

* First full term pregnancy or first live-birth.

† Raw odds ratio and confidence interval calculated by StatXact. 
their analysis was also restricted to parous women. Another salient feature of this study is a non-cancer outpatient control population slightly older than the patient population (approximate median ages, 53 versus 48, respectively).

In addition to describing the oldest data set in the literature on induced abortion and breast cancer, the 1968 study of Watanabe and $\mathrm{Hi}$ rayama $^{15}$ is also unique in that the 238 breast cancer patients are compared to 110 stomach cancer patients as controls. Here again, controls were slightly older than cases (approximate median age, 48 versus 43 , respectively).

The 1978 study by Dvoirin and Medvedev ${ }^{18}$ concerned 227 Russian and Kabardin patients and 500 controls in the former Soviet Union. It was reviewed in English by Remennick, ${ }^{12}$ who reported RR estimates of 2 for one or two induced abortions and 3.4 for three or more induced abortions. However, these data are given for induced and spontaneous abortion combined in the original study. ${ }^{18}$ Where the original study does show data specifically relating to induced abortion, it shows only dichotomous data for induced abortion in Kabardin $(R R=1.4)$ and Russian $(R R=1.89)$ women (combined $R R=1.71$ ), but without showing any significance values, confidence intervals, or raw data. Hence, we developed a computer program to find all possible exposures for a population of 227 patients and 500 controls which would yield an OR of 1.71. Out of all the possibilities, the one which yielded the widest $95 \%$ confidence interval (CI) $(0.80,3.64)$ was taken as the most conservative estimate for inclusion in the meta-analysis.

The 1979 study of Burany ${ }^{52}$ compares 250 Yugoslavian breast cancer patients with an equal number of healthy controls matched for age, ethnicity, and residence. This study is unique in the high rate of exposure, with $60 \%$ of cases and $75 \%$ of controls showing a history of between 1 and 20 induced abortions. It is also the only case-control study to report a statistically significantly reduced breast cancer risk, although the difference is almost entirely represented by subjects who reported one induced abortion. It is also noteworthy that this study produced atypical risk profiles for reproductive variables, showing neither any tendency toward increasing risk with age at first live birth, nor toward decreasing risk with parity.

The 1981 study of 163 young white American breast cancer patients by Pike et $a l^{49}$ is perhaps the best known study in the field. In fact, it has often been referred to as the first study to report an increased risk of breast cancer in women who had experienced induced abortion, ${ }^{45}$ although it appeared almost a quarter century after the more powerful study of Segi et al. ${ }^{1}$ The restriction to subjects under 33 years of age at diagnosis is unusual, but justified by the fact that induced abortion had only been legalised in the US about the time of the beginning of the data collection period (1972-78). The analysis is also restricted to abortion before first full term pregnancy. Cases were age matched both to healthy "neighborhood" and "friend" controls, and, although
$R R$ calculations are presented for spontaneous and induced abortion combined, raw data are given, so that the crude OR may be calculated specifically for induced abortion. In calculating the crude OR, we opted to compare exposed subjects with those who simply had no exposure to induced abortion, rather than with those who had no abortion of either type, thus generating a more conservative point estimate $(2.37$ versus 2.50). A subsequent study of this population with additional patients and controls, ${ }^{44}$ did not differentiate between induced and spontaneous abortion.

The 1982 study of Nishiyama ${ }^{16}$ compared 767 radical mastectomy patients from a single prefecture in Japan with an equal number of age matched, normal controls identified through a mass breast cancer screening programme. The median age of patients and controls was approximately 51 years.

The 1983 study of Brinton et $a t^{3}$ involved 1362 cases and 1250 healthy control subjects, all identified between 1973 and 1977 through a mass screening programme in 28 centres in the US. Patients and controls were race matched and age matched within five years, with a median age of approximately 53 years. Despite the large study population, however, the then very recent nature of induced abortion legalisation severely limited the number of exposures reported. In fact, although raw data were incompletely reported, it appears that only about 20 cases had any history of induced abortion. Curiously, although the calculation of an OR of 2.2 for abortion before first full term pregnancy is in close agreement with that (2.37) of Pike et $a l,{ }^{49}$ Brinton et $a l^{3}$ characterised their findings as "contrary to Pike $e t$ al (1981)".

Le et $a{ }^{4}$ studied 240 French breast cancer patients under age 46, diagnosed between 1982 and 1984, with the aim of measuring the effect of oral contraceptive use. Patients were matched with hospital controls ( \pm 2 years in age), $22 \%$ of whom had non-gynaecological malignancies. Induced abortion history was taken as one of "nine classical risk characteristics", considered by the authors to be potential confounding variables for oral contraceptive use.

The 1985 paper by Hirohata et $a \Gamma^{1}$ describes the first third of a cooperative study of breast cancer among Japanese women in Japan, Japanese women in Hawaii, and white women in Hawaii. The study was designed to examine the role of dietary and reproductive history, but apparently, data were never collected on either spontaneous or induced abortion in the $\mathrm{Ha}$ waiian parts of the study. The Japanese patients numbered 212, with 212 matched (for age within 5 years) hospital controls without cancer or breast disease and 212 random neighborhood controls. An unusual finding of this study was a null association with family history of cancer.

In their 1988 study, Ewertz and Duffy ${ }^{55}$ compared reproductive histories in 1486 Danish breast cancer patients diagnosed during 1983 and 1984, and who were under 70 years old (median age approximately 53 years), with 
1336 control women drawn at random from the general population and stratified by age in decades. The only data given which specifically related to induced abortion were for nulliparous women. Although this RR was reported as 3.85 and significant, since the reference group consisted entirely of parous women, this figure represents the combined effect of nulliparity and induced abortion. Fortunately, the authors also calculated the RR of nulligravid women, compared with parous women. Thus, we were at least able to calculate a corrected RR of 2.91 for nulliparous women (table 2).

The 1988 study of Rosenberg et $a \bar{l}^{6}$ is a continuation of the 1983 study of Helmrich et $a l,{ }^{39}$ which did not separate induced and spontaneous abortion data. Although this study includes data from four major east coast cities and includes 3200 cases and 4844 cancer free hospital controls under 70 years of age, it is severely weakened by a very large age difference and a consequent cohort difference in induced abortion exposure rates between cases and controls. In particular, since the subjects were collected between 1978 and 1985, and since the median patient age was $\mathbf{5 2}$ and the median control age 40 years, the average patient in the study was in her 40's, but the average control subject was only about 30 when induced abortion was legalised nationwide in 1973. In fact, more than three times the number of controls $(49 \%)$ as patients $(16 \%)$ in the study were under age 40 . Nevertheless, an overall RR of 1.2 (with borderline significance) emerges when the data for all ages and parities are combined (table 2).

The 1989 study of Howe $e t a l^{77}$ reports data on all 1451 women from upstate New York (including Long Island) under the age of 40 who were diagnosed with breast cancer between 1976 and 1980 . Since this age matched, neighborhood control study was based entirely on computerised records, the possibility of recall bias was eliminated, although the possible effects of certain variables such as family history could not be evaluated. Unfortunately, data presented on abortion before first full term pregnancy did not distinguish between induced and spontaneous abortion. A particularly noteworthy finding of this study is of 10 patients and no controls with a history of two consecutive induced abortions.

The 1989 study of Harris et $a l^{8}$ is a computerised registry study of the cohort of Swedish women who had induced abortions during the period 1966-74. Although the prospective nature of the study precludes the existence of response bias, the study nonetheless suffers from serious methodological weaknesses. Firstly, the incidence of breast cancer among subjects who had undergone induced abortion was compared with the expected incidence from general population statistics. These statistics included the study cohort and were not adjusted for the protective effect of parity, even though the nulliparity rate was considerably higher among the general population (49\%) than the study cohort $(41 \%)$. Secondly, the authors inexplicably restricted their study cohort to those whose abortion occurred before age 30 . This had the effect of disproportionately eliminating older breast cancer patients from the analysis, as the authors' own comparison of "total cohort" versus "study cohort" data shows. However, a case-control study with overlapping authorship and most of the study population in common was published by Adami et $a P^{9}$ in 1990 . This latter study includes 317 Swedish patients (with one age matched, nonhospital control each) and 105 Norwegian cases (with two age matched controls each) under the age of 45 and 40 years, respectively, and diagnosed during 1984-85. As noted above, the Swedish population is largely included in the computerised cohort study of Harris et al, ${ }^{58}$ but we have chosen the better designed, casecontrol study ${ }^{59}$ for inclusion in the overall OR calculation of the meta-analysis to represent this population (category 1 , table 2 ), although the point estimates do not differ substantially between the two studies $(0.77$ versus 0.9 , respectively). Concerning data pertaining to abortion before first full term pregnancy, Harris et $a b^{8}$ reported data for women who were nulliparous versus parous at the time of abortion, who are thus included in the meta-analysis under category nos 2 and 3 (table 2). However, the OR for abortion before first full term pregnancy among women parous at diagnosis is only given in the study of Adami et al. ${ }^{59} \mathrm{Un}$ fortunately, the OR for this statistic given in the paper $(0.6 ; 95 \% \mathrm{CI}: 0.3,1.5)$ does not include multiple abortions, for which the authors did not calculate an OR. We have therefore recalculated the $\mathrm{OR}$ for one or more abortions using the raw data given. The value thus obtained $(0.82 ; 95 \% \mathrm{CI}: 0.44,1.51)$ is included in the meta-analysis under category 2b (table 2).

A continuing case-control study in the greater Milan area of northern Italy has generated a number of published reports, four of which $^{60-63}$ have included data specifically on induced abortion. The most recent, a 1993 report by La Vecchia et $a t^{63}$ is a summary of data on many types of cancer, including 3048 breast cancer cases and 4981 cancer free, hospital controls. In this report, the data on breast cancer are limited to overall risk among subjects with one or two or more induced abortions, which we have combined for category 1 in the meta-analysis (table 2). Data from the 1987, ${ }^{60}$ $1991,{ }^{61}$ and $1992^{62}$ reports, are superseded by those of the 1993 paper. ${ }^{63}$ The 1991 paper by Parazzini et $a l^{61}$ also reports RRs for abortion before first birth, but only distinguishes between induced and spontaneous abortion in nulliparous women (440 cases and 449 controls). Hence, data from this report are included in the meta-analysis under category 2a (table 2). An unusual feature of this study population is the lack of a significant overall trend in risk with respect to parity, with subjects with 1-3 children showing raised (1.2-1.4, but not statistically significant) risks, and those with four or more children, slightly (0.8) but significantly reduced risk.

The 1993 study of Moseson et $a l^{64}$ on 370 breast cancer patients and 783 normal controls from a New York City screening clinic is un- 
usual in several important respects. Firstly, the study was published many years after its completion, with patients diagnosed in the half decade of 1977-81. Since most cases and controls were postmenopausal, very few would have been exposed to induced abortion, which had only been legalised in New York in 1970. Secondly, this cohort effect is compounded by substantial differences in age between cases and controls. The authors acknowledged that cases were an average of 3 years older than controls; thus more of them were postmenopausal. More importantly, almost twice as many controls as patients $(16.1 \%$ versus $8.9 \%$, respectively) were in the $22-44$ year age stratum, the only age stratum that would have had any significant exposure to legally induced abortion. Hence, despite adjustment of the OR for age in the analysis, considerable underestimation of the overall $R R$ for induced abortion might be expected. This difficulty appears to have been avoidable, since the table giving the distribution of subjects according to age indicates a large excess of controls in every stratum, and an age matched control group could therefore have been selected. A third potential difficulty is the likelihood of partial overlap of the study population with that of the study of Rosenberg et al, ${ }^{56}$ whose cases were gathered during 1978-85, and included cases from two large prestigious hospitals in New York City. Since Moseson et a $t^{64}$ collected cases from the most prominent screening centre in New York City, it may be assumed that some of these cases ended up in both studies. Another unusual feature of this study is that the number of induced abortions was ascertained indirectly by subtracting the number of births and miscarriages from the number of total pregnancies, since the authors considered induced abortion history "too sensitive a question", and acknowledged that it "may have resulted in an underestimate of the abortion rate in the study group".

The 1993 study by Laing $e t a l^{65}$ is exclusively on African-American women, specifically, 503 cases from the Washington, DC area who were diagnosed between 1978 and 1987, and 539 non-cancer hospital controls matched for age (5 year age groups). Most of the cases and controls in the study were postmenopausal (mean age: 57.2 and 56.1 years, respectively). Both crude and adjusted (by multiple logistic regression) ORs are presented, with the latter (which are used in the present meta-analysis) limited to 405 cases and 463 controls for whom complete data were available. For induced abortion, the data were reported for three age strata, and the OR went up with age, reaching 4.7 in subjects age 50 and over. In the metaanalysis (category 1) we have combined the ORs given for the three age strata (table 2).

The 1994 study by Laing et $a l^{66}$ has so far only been published as an abstract. It also is exclusively on African-American women from the Washington, DC area, but the cases were diagnosed between 1989 and 1993. Only overall ORs (category 1) obtained by conditional logistic regression analysis are presented for the 138 patients who had at least one unaffected sister, with these sisters serving as paired controls. While this novel study design at least partially eliminates the confounding effect of family history, it is likely that the sister controls were generally younger than the patients, a feature which would tend to inflate the OR. It also is likely that age was adjusted for in the analysis, although this is not stated in the abstract.

The 1994 study of Andrieu et $a b^{67}$ focused on the interaction of abortion and family history. The study population is comprised of 495 cases, 354 "friend or colleague" controls, and 431 non-cancer hospital controls, all obtained between 1983 and 1987 from a study on oral contraceptive use and breast cancer. The age range of subjects was $20-56$ years, with a mean of approximately 44.5 years for patients and both control groups, even though they had been only matched to \pm 5 years. Of particular note is the interaction of induced abortion and family history of breast cancer (mother, sister, grandmother, or aunt). Among subjects reporting a positive family history and one induced abortion, an OR of 1.3 (non-significant) was calculated, which rose to a significant 7.1 among subjects reporting two or more induced abortions.

The 1994 studies of White et $a l^{88}$ and Daling et $a l^{\beta}$ concern essentially the same white patient population derived from a tumour registry in Washington state - patients aged 45 and under who were diagnosed between 1983 and 1990 . Controls were identified from the general population through random digit telephone dialing, and appear to be about 2 years younger than the patients, on average. The only difference in the patient population of the two studies is that the former $(n=747)$ was restricted to invasive cancer, while the latter $(n=845)$ also included 98 patients with in situ carcinoma. Both studies used the same control group. The former study ${ }^{68}$ was designed primarily to investigate the effects of oral contraceptive use on breast cancer risk, while the latter ${ }^{3}$ focused on induced abortion. However, due to differences in study design, we have elected to include some of the data from each study in the meta-analysis, for the following reasons. White et $a l^{88}$ calculated ORs for induced abortion using the entire patient and control populations for the calculation. However, Daling et $a^{\beta}$ restricted their calculations of all ORs concerning induced abortion to women who were ever pregnant (689 cases and 781 controls). The effect of thus deleting the nulligravida is to arrive at an estimate of the risk associated with induced abortion and nulliparity combined. Not surprisingly, therefore, the OR based on women who were ever pregnant $(1.5)^{3}$ is slightly higher than that based on the entire study population (1.36) ${ }^{68}$ Therefore, we have elected to use the more conservatively estimated data of White $e^{2} a^{78}$ in the meta-analysis for category 1 (table 2). Data pertaining to abortion before versus after first full term pregnancy (categories $2,2 \mathrm{a}, 2 \mathrm{~b}$, and 3 ; table 2) are only given by Daling et $\mathrm{al}^{3}$

The 1995 study of Brinton et $a l^{69}$ is focused on the effect of oral contraceptives on breast 
cancer risk, and shows only data for one and two or more induced abortions in women who were ever pregnant. The 1648 patients (with invasive or in situ carcinoma) and 1505 controls were drawn from three regions of the US: Atlanta, Georgia, central New Jersey, and the same Seattle, Washington area covered earlier by the studies of White et $a t^{68}$ and Daling et $a l^{\beta}$, with subject collection in the Seattle area beginning when that of the previous studies left off - ie, mid-1990, and ending with the end of 1992. Patients in the Brinton et al study ${ }^{69}$ also appear to be slightly older than controls. An unusual feature of this study is the adjustment for race (white, African-American, or "other"), rather than keeping the study uniracial or matching for race. The authors' calculation indicating an OR of 1.20 for AfricanAmerican women is not surprising, since it is known that breast cancer incidence is higher in premenopausal African-American women than in white American women. However, it is a cause for concern that ORs for other variables, such as induced abortion, are adjusted for this difference, since the reason for the racial difference is unknown, and since AfricanAmerican women are vastly over represented among induced abortion patients. Thus it is possible that adjustment for race, rather than eliminating the effect of a confounding variable, actually nullifies the effect of the variable under study. Another question is raised by the fact that all information on control subjects was truncated at the time of initial screener interview, but the authors do not indicate that the period during which the controls were screened for participation is the same as the period during which patients in the study were diagnosed. If these periods did not overlap precisely, any differences would constitute an additional source of error. It is expected that Brinton and colleagues will publish a sequel to this study focussing on induced abortion, at which time the results may be more fully evaluated.

The 1995 study of Greek women by Lipworth et al involved 820 patients, (diagnosed during the years 1989 through 1991), 795 cancer free hospital controls, and 753 "healthy visitor" controls. Although controls were matched for age and residence, the age matching was crude ( \pm 5 years), and age distribution data were not given. Hence significant age discrepancies between cases and controls may exist.

The 1995 study by Rookus and van Leeuwen $^{70}$ has so far only been presented as an abstract. It is a population based study of 918 case-control matched (for age and region) pairs, all under age 55. Cases were diagnosed between 1986 and 1989 and originally gathered for a study on oral contraceptives and breast cancer risk. Dichotomous data are given for overall induced abortion, as well as for the timing of induced abortions relative to first full term pregnancy. As in the studies of Daling et $a l^{\beta}$ and Brinton et $a l,^{69}$ ORs are calculated exclusive of nulligravida - ie, for women who were ever pregnant.
The 1996 study of American women by Newcomb et $a l^{1}$ is a very large study, with 6888 patients obtained from tumour registries and 9529 non-hospital controls, and with subjects (under 75 years old) drawn from Wisconsin, Massachusetts, Maine, and New Hampshire. However, most of the abortions reported among cases and controls $(97 \%)$ were spontaneous. It is also noteworthy that, in the same manner as in the 1995 study of Brinton et $a l,{ }^{69}$ information on control subjects was truncated at the time of screener interview, with the timing of this collection period (relative to diagnosis dates) not given. Any deviations from the precise overlap of these periods may result, for example, in patients and control subjects with identical birth dates being considered as having different ages. A unique feature of this study is the establishment of an arbitrary gestation length of six months, beyond which all pregnancies are characterised as full term. While excluding late term abortion from the analysis would be acceptable, including them in a category expected to have an opposite (ie, downward) effect on risk, is questionable. Of particular concern is the exclusion of 66 cases and 50 controls for whom the precise timing of pregnancy termination was not known with respect to the six month dividing line. Since 66 cases represent, proportionately, twice as many subjects as 50 controls, a significantly (twofold) raised risk among these women is thus ignored. Although these authors also reported having found no statistically significant differences regarding timing of abortions relative to full term pregnancies (categories 2 and 3) or number of abortions, no data for these subgroups are given. Finally, this study evidences a trend, similar to that found by Laing et $a l^{65}$ of increasing risk with age at diagnosis (divided into five 10 year age strata). Thus, the reported $R R$ of 1.11 for women under 40 years of age at diagnosis rises to 2.02 for women age 70 and over.

\section{STATISTICAL METHODS}

Descriptive statistics were presented as ORs or RRs in all studies included in this review, except in the case of Segi et $a l,{ }^{1}$ from which ORs were calculated as described previously. Except for five studies which reported only raw ORs, ${ }^{1516185257}$ a multiple logistic regression analysis was used to arrive at an estimate of the OR, adjusted for age and other prognostic factors such as parity and age at first full term pregnancy (or age at first live birth). In addition, one of the studies reporting only raw ORs also stated that the use of the conditional binomial distribution did not change the ORs. ${ }^{57}$ Seven of the studies in the meta-analysis did not report an overall dichotomous OR (category 1), but rather, reported separate ORs on the basis of single versus multiple exposures, ${ }^{16546869}$ differences in age at diagnosis, ${ }^{65}$ or differences in parity. ${ }^{536}$ For these studies, the overall dichotomous OR and $95 \%$ CI were calculated for each study according to a weighted average formula using the natural logarithm of the given 


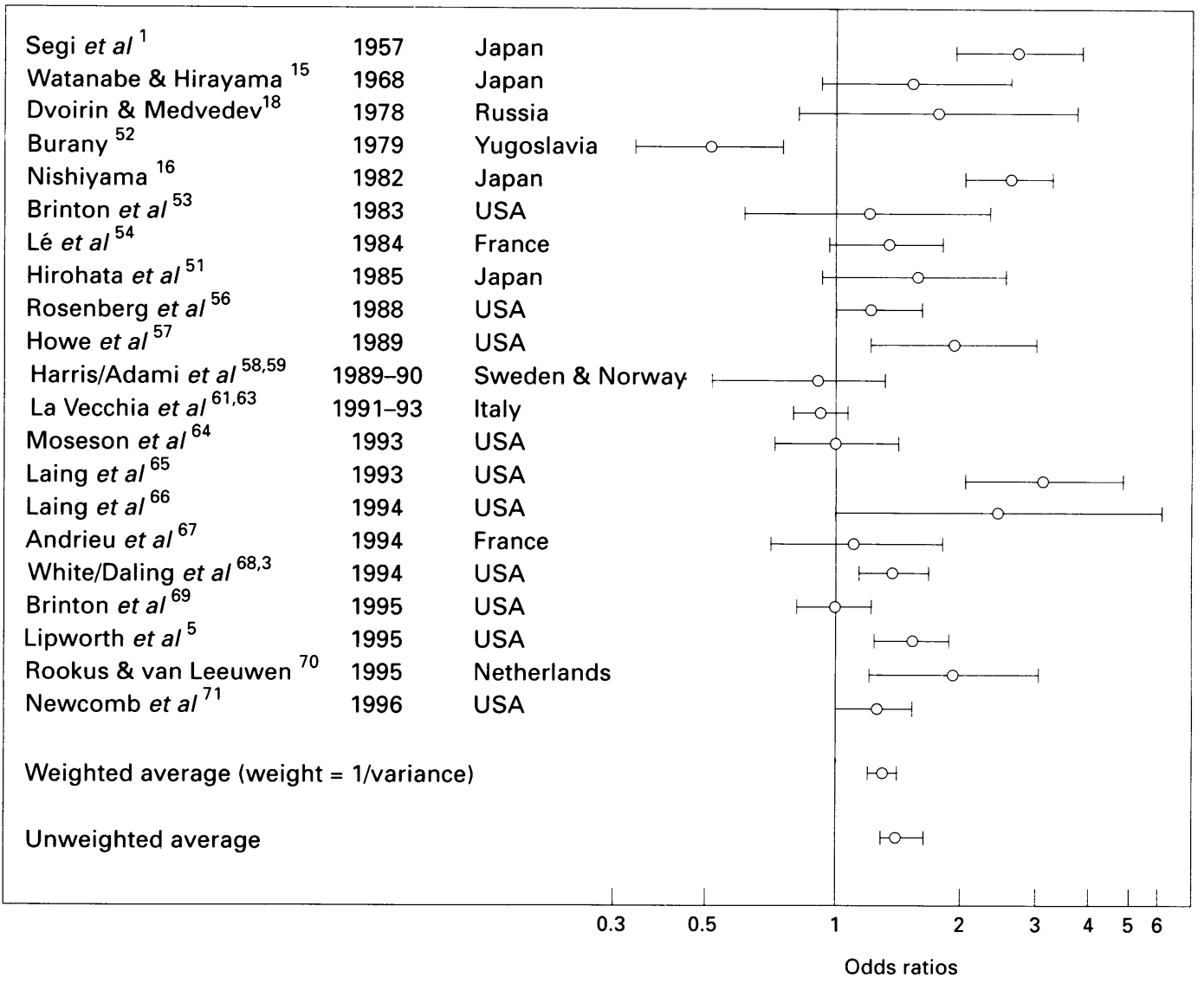

Figure 1 Overall odds ratios (ORs) for any induced abortion history (category 1, table 2). Point estimates and 95\% CIs for each component study, and for weighted and unweighted average are plotted on a logarithmic scale.

OR and the inverse of the variance. ${ }^{72}$ For those studies which did not use logistic regression, we calculated exact $95 \%$ CIs for the ORs via StatXact (Cytel Software Corp., Cambridge, MA, USA).

For the meta-analysis, a weighted average for the pooled OR was obtained for each exposure category using the log $\mathrm{OR}$ and inverse of the variance as described above. For overall, dichotomous exposure (category 1), the unweighted average was also calculated for comparison (figure 1).

\section{Results}

Figure 1 shows a semi-logarithmic plot of the overall dichotomous ORs and 95\% CIs (error bars) for induced abortion and breast cancer (category 1) for each of the 21 independent studies for which such data were presented (representing data published in 26 separate reports) or could be calculated (see Statistical methods). The weighted $(1.3,1.2-1.4)$ and unweighted $(1.4,1.3-1.6)$ averages, both of which significantly exceed unity, are also shown.

Table 2 lists the ORs and CIs for each of the 23 independent studies (representing data published in 28 separate reports) included in the meta-analysis for each category for which data were reported. Table 3 summarises the weighted averages and $95 \%$ CIs for each category. All of the averages significantly exceed unity.

Table 4 lists the proportion of studies for each classification with (a) an OR greater than unity, (b) a significantly positive OR and (c) a significantly negative OR. For each classification, a majority of the studies exhibited an estimated OR greater than unity. Of the significant findings for each classification, the positive results outnumbered the negative results. In particular, there were 10 significantly positive findings and only one significantly negative finding out of 21 independent studies for category 1 .

\section{Discussion}

INCLUSION, EXCLUSION, AND WEIGHTING

In the present work, we have endeavored to be as conservative and as inclusive as possible, thus to avoid introducing any subjective biases of our own through such means as the imposition of quality criteria. Hence, the single 
Table 4 Direction of association between induced abortion and breast cancer in component studies of meta-analysis

\begin{tabular}{|c|c|c|c|c|}
\hline Exposure category & Parity at $D x$ & $\begin{array}{l}\text { Proportion of } \\
\text { ORs }>1(\%)\end{array}$ & $\begin{array}{l}\text { Proportion of significantly } \\
\text { positive ORs }(\%)\end{array}$ & $\begin{array}{l}\text { Proportion of significantly } \\
\text { negative ORs (\%) }\end{array}$ \\
\hline $\begin{array}{l}\text { Any } \\
\text { Before FFTP } \\
\text { Before FFTP } \\
\text { Before FFTP } \\
\text { After FFTP }\end{array}$ & $\begin{array}{l}\text { Any } \\
\text { Any } \\
\text { Nulliparous } \\
\text { Parous } \\
\text { Parous }\end{array}$ & $\begin{array}{cl}16 / 21 & (76) \\
7 / 7 & (100) \\
4 / 7 & (57) \\
4 / 6 & (67) \\
4 / 6 & (67)\end{array}$ & $\begin{array}{cc}10 / 21 & (48) \\
2 / 7 & (29) \\
1 / 7 & (14) \\
3 / 6 & (50) \\
3 / 6 & (50)\end{array}$ & $\begin{array}{ll}1 / 21 & (5) \\
0 / 7 & (0) \\
0 / 7 & (0) \\
0 / 6 & (0) \\
1 / 6 & (17)\end{array}$ \\
\hline
\end{tabular}

FFTP $=$ first full term pregnancy or first live-birth

exclusion criterion is the absence of data relating specifically to induced abortion.

Nevertheless, maximal inclusion of published studies also may introduce error in two ways, namely, by repetition of data due to overlap of study populations, and by the sometimes wide variations in study quality. We have addressed the former problem with care to include only one data set for studies wherein the overlap of study populations was nearly complete, as in the studies of Harris et $a P^{8}$ and Adami $e t a l^{59}$ and those of White et $a l^{88}$ and Daling et $a l^{\beta}$, and wherein one study superseded another as a more recent report of a continuing study, as in the studies from northern Italy. ${ }^{60-63}$ In the case wherein overlap of a small proportion of study subjects was likely - ie, in the studies of Rosenberg et $a b^{66}$ and Moseson et al ${ }^{64}$ - we have chosen to include both as separate studies. However, it is noteworthy that the overall ORs of these two studies were similar (1.2 and 1.0, respectively), and the possible error (in the direction of underestimation of the overall $\mathrm{OR}$ ) due to the partial overlap would necessarily be slight. Regarding differences in study quality, we have chosen the most widely accepted and objective method of weighting, namely, according to the inverse of the reported variance of the $\log \mathrm{OR}$. For comparison, we have also calculated the unweighted average of the overall OR, and, although its CI is (not surprisingly) somewhat wider, the point estimate $(1.4)$ is very close to the weighted average (1.3), and both are significant. Acknowledging, however, that no statistical formula could possibly account for the many large and small differences in study design and descriptive statistical presentation in the various reports, we also have opted to include a rather detailed narrative review of the individual included studies as well as the individual data entered into the quantitative meta-analysis. By this method, we have aimed to provide the reader with as complete as possible a qualitative as well as quantitative review of the extant literature. Ideally, a meta-analysis would be based on a compilation of the raw data (including data on other prognostic variables) from each subject from each component study. A logistic regression analysis could then be applied to the master data base to get a more reliable estimate of the overall OR. With such a database it might even be possible to perform more sophisticated statistical analyses than logistic regression, such as proportional hazards regression of the age at time of breast cancer diagnosis.

Another general limitation to the present meta-analysis is the observational nature of studies on abortion and breast cancer, since observational studies inherently contain more bias than randomised trials. Recent discussions in the literature ${ }^{73-77}$ have addressed the concerns that arise with claims of causality when relatively small ORs are reported, whether in a single study or in a set of studies. Given the relatively small magnitude of the cumulative ORs (table 3) we have calculated, the question arises as to whether these are real effects or artifacts of the biases that occur within observational studies. One attempt to distinguish artifact from reality is to look for consistency across the independent studies. Table 4 illustrates the clear consistency that emerges in the present meta-analysis, with the overwhelming majority of the studies favouring a positive association.

\section{THE “FILE DRAWER" PROBLEM}

In any meta-analysis, the "file drawer" argument may be invoked, particularly if the magnitude of both the individual and cumulative ORs (tables 2 and 3 ) is small. That is to say, if there is an underlying bias against the publication of negative data, the significantly elevated ORs generated by the present metaanalysis may be artefactual. However, since induced abortion is an unusual surgical procedure which is politically and legally, as well as personally, sensitive, there is indirect evidence to suggest the opposite trend in bias, that is, against the publication of data which reflect a positive association with breast cancer incidence.

It is certainly understandable that the first observation of increased breast cancer risk with induced abortion should have been interpreted with caution. For example, Segi et al ${ }^{1}$ back in 1957, having observed that, "The rate of artificial interruption of pregnancy is significantly larger in all the subgroups among the cancer cases than the control cases", were nonetheless "rather hesitant ... in inducing some definite conclusions". However, it is peculiar that almost 40 years and over 20 , mostly positive studies later, the most recent investigators should report their own, significantly positive data with extraordinary reluctance. Witness the literal bottom line of the recent report of Newcomb et al $l^{1}$ : "our data suggest that the risk of breast cancer associated with any pregnancy termination is likely to be small, if it exists at all".

Perhaps the most widely known study which reported a positive association between induced abortion and breast cancer is that of Pike et $a l^{49}$ in 1981 , on young women in California. 
The following year, Vessey et $a l,{ }^{14}$ in their own study at Oxford, called the findings of Pike et $a l$ "provocative and worrying" and offered their own (slightly and insignificantly negative results) as "entirely reassuring", even though their study population contained "only a handful" of subjects with induced abortion, and was therefore inadequate to address the issue of induced abortion and breast cancer risk at all. Finally, the conspicuous absence of any mention of induced abortion relative to breast cancer risk in prominent medical journal reviews (eg, the New England fournal of Medicine ${ }^{6}$ and Lancet $^{7}$ ) may be seen against the conspicuous claim, by the American Medical Association in its own Journal, ${ }^{78}$ as recently as December of 1992, that the risk of maternal death from childbirth is, at "a conservative estimate" (of 4.7 deaths per 100000 live births) "nearly 12 times greater than the legal abortion mortality ratio of 0.4 ". Lifetime breast cancer risk is currently estimated to be approximately $12 \%$ in the US, for example, where induced abortion is a very common exposure (approximately 1.6 million per year). Thus, it is easily seen that any demonstrable risk increase due to induced abortion would make this elective procedure far more risky than live birth, at least in the long term, as the risk of immediate maternal death is vanishingly small for any pregnancy outcome. Therefore, while we are aware of no specific cases wherein positive data have been withheld from publication, indirect evidence suggests that any bias against publication of data concerning induced abortion and breast cancer would be in the direction of keeping positive rather than negative data "in the file drawer".

RECALL OR RESPONSE BIAS

The possibility of bias due to differential recall and/or reporting by patients versus control subjects merits serious consideration in any retrospective questionnaire or interview based study. It looms still larger as a possible confounding variable in any association of low magnitude, particularly when such a sensitive exposure as abortion is in question.

With regard to abortion and breast cancer, the issue of recall bias was raised by Harris et $a e^{8}$ in 1989 as an explanation for the already clear trend in worldwide data: "Most of the earlier epidemiological studies showed increased risk among women who had had an abortion; one reason for this could be recall bias". In particular, these authors ${ }^{58}$ postulated that recall bias would be in the direction of exaggerating $R R$, on the supposition that, " $A$ women with cancer is perhaps more likely to remember and report a previous abortion than a healthy control".

A test of this hypothesis was subsequently published by the same group in $1991 .^{79}$ In this study, the authors compared prospective, computerised data reported in their 1989 study $^{58}$ with data on the same Swedish study population that had been gathered by retrospective interview for an earlier $(1986)^{80}$ study on oral contraceptives and breast cancer. As evidence of response bias, the authors reported a differential discordance between computer registry based data and interview based data, specifically, that an excess of cases relative to controls ( 7 versus 1 , respectively) had "over reported" induced abortions, and that an excess of controls relative to cases (16 versus 5 , respectively) had "under reported" induced abortions. ${ }^{79}$ From these discrepancies, the authors calculated that the OR for induced abortion based on the interview data (0.95) was significantly inflated compared with that based on the computer registry data $(0.63$; ratio of the ORs $=1.5,95 \%$ CI 1.1,2.1). ${ }^{79}$

With regard to the issue of "over reporting" in this study, ${ }^{79}$ we do not hesitate to concur with Daling et $a l^{3}$, who commented, "we believe it is reasonable to assume that virtually no women who truly did not have an abortion would claim to have had one". Daling et $a l^{\beta}$ went on further to recalculate the $O R$ inflation reported by Lindefors-Harris $e t a l^{79}$ with all positive reports of induced abortion history (whether by interview or computer) taken as true, and they showed that the spurious risk increase went down from a significant, $50 \%$ to a non-significant $16 \%$, attributable to the "under reporting" among controls.

Even closer scrutiny reveals the claim of "under reporting"79 to be on no firmer ground than that of "over reporting". ${ }^{79}$ The 1986 study, from which the interview based data were gathered, ${ }^{80}$ contained no abortion data, which were instead reported in the 1990 study of Adami et al. ${ }^{59}$ There was, however, a single difference in the study populations between the 1986 and 1990 reports: The latter ${ }^{59}$ had one control subject, obtained from a population register, for each of the 317 Swedish patients, including the 196 who were under 40 years old at diagnosis, but the former study ${ }^{80}$ had had an additional control selected from a fertility register for each of the cases under 40 . The only segment, it turned out, of the 1991 study population to show a substantial discordance attributable to under reporting, was the control population under 40 years old, with 12 control subjects (compared with only four patients) reporting no induced abortions, but for whom abortions were listed on the computer registry. It is not possible to determine from the published data if most (or even all) of these under reporting control subjects were from the extra, fertility register control group ${ }^{80}$ which was not used in the 1990 study. ${ }^{59}$ However, it seems reasonable to postulate the existence of response bias between subjects solicited from a tumour registry or a population registry versus those solicited from a fertility registry. That is, women whose names were obtained from a fertility register, who are thereby identified as mothers by the interviewers, might be more reluctant to admit having had any abortions than women identified merely as women or as citizens. Unfortunately, the deletion of the fertility register controls ${ }^{80}$ from the 1990 report was not explained. ${ }^{59}$ In any event, it is clear that the 1991 paper $^{79}$ does not provide credible evidence of response bias between cases and controls. 
Daling et $a l^{\beta}$ also offered, as further evidence against the response bias argument, their own finding of a null association of cervical cancer and induced abortion among 214 cases and 321 controls gathered and interviewed in the same manner as those in their breast cancer study. Nevertheless, despite the compelling case made by Daling $e t$ al ${ }^{\beta}$ against a response bias interpretation of their own data, Rosenberg, in her accompanying editorial, ${ }^{4}$ maintained that "the possibility of reporting bias" was "a major concern" in the study, with no acknowledgment whatsoever that Daling et al had indeed addressed the issue.

Outside of the study of Harris et al, ${ }^{58}$ the only other computer registry based study of induced abortion and breast cancer is that of Howe et al, ${ }^{57}$ which contains direct evidence against the response bias hypothesis. In interpreting their finding of significantly raised risk (table 2), these authors noted "under reporting" and "inconsistent reporting" on the fetal death certificates. However, they found no evidence of bias, with instances of such misreporting having "occurred similarly among the cases and the controls". ${ }^{57}$

More recently, Lipworth et af suggested that their own study on women in Greece, with its "permissive social environment with respect to induced abortion", might therefore "provide a useful complementary insight" in order to test hypotheses that "have been invoked to explain, in noncausal terms, the reported association between induced abortion and breast cancer". They concluded that their own data (in excellent agreement with those of Daling et $a l^{\beta}$ and Howe et $a P^{7}$; table 2) did not result from response bias, since "healthy women in Greece report reliably their history of induced abortion". ${ }^{75}$

Despite the overwhelming evidence that the association of induced abortion and breast cancer does not result from reporting bias, the response bias argument continues to be advanced with vigour. Recently, Rookus and van Leeuwen $^{70}$ attributed their significantly higher OR obtained from a more rural and traditionally religious region of The Netherlands (compared with a highly urbanised region) to "differential misclassification bias". Surely this is but one of many possible explanations for different results between two regions with substantial differences in many variables, including ethnicity and a host of lifestyle factors. It is also noteworthy that the exposure rates for both regions are very low, and that both show positive overall associations between induced abortion and breast cancer. Also recently, Newcomb et $a l^{1}$ have claimed that their results "suggest a bias in reporting", since the RR is slightly higher among American women with induced abortions before versus after legalisation in the US in $1973(1.35,95 \%$ CI 1.01, 1.80 versus $1.12 ; 0.84,1.49$, respectively). However, their data speak for themselves: Each of these point estimates falls well within the other's CI, thus providing no support for the suggestion of reporting bias. On the contrary, the almost significant $(p=0.09)$ trend they report for RR to increase with age at diagnosis is continuous, and it shows up even when only post-1973 abortions are included. ${ }^{71}$

SPECIFIC EFFECT OF INDUCED ABORTION VERSUS DELAYED CHILDBIRTH

A crucial consideration in the assessment of the real magnitude of breast cancer risk attributable specifically to induced abortion is the ability to distinguish this from the known increased risk attributable to a delay in the first full term pregnancy by any means. ${ }^{81}$ From the point of view of women considering abortion, parous women would be subject only to the independent effect of induced abortion, whereas nulliparous women (about half of American abortion clients), would be subject to both risk enhancing effects of the abortion, depending on their age at time of abortion and if and when they subsequently have any children.

From the point of view of breast cancer aetiology, delay of first full term pregnancy is one of only two risk factors (the other being ionising radiation) known to influence primary carcinogenesis. Presumably, delaying the first complete pregnancy increases the time period during which undifferentiated breast tissue can accumulate potentially tumourigenic mutations. Induced abortion, however, may independently increase risk via the tumour promoting effect of the considerably raised oestradiol concentrations of early pregnancy, while denying a woman the benefit of the differentiating effect of the hormonal milieu of late pregnancy. This differentiating effect is presumably the mechanism by which an early, completed pregnancy confers permanent protection against breast cancer. ${ }^{28182}$ In addition, induced abortion may enhance the oestrogen mediated proliferation of normal but primitive cells, resulting in the presence of more cells which are vulnerable to subsequent primary carcinogenesis.

From the point of view of epidemiology, the differential effects of delaying the first full term pregnancy and artificially terminating a pregnancy in progress have been resolved in two ways. Firstly, by assessing the risk of breast cancer specifically in populations of nulliparous women, the specific effect of induced abortion can be measured, providing the controls include the nulligravida. In the present metaanalysis, only seven studies assessed risk in nulliparous women. ${ }^{355355566170} \mathrm{Six}$ of the seven used nulliparous women (all but one ${ }^{3}$ including the nulligravida) as controls. Only Ewertz and Duffy $^{55}$ used only parous women as controls, but since they also provided data on the risk of nulliparity per se, we were able to subtract out this effect in order to arrive at the net $R R$ attributable specifically to induced abortion in nulliparous women in their study (table 2). The resulting pooled OR in the meta-analysis (category $2 a$, table 3 ) is the same as that of the overall OR (category 1).

The second method of arriving at the specific overall effect (ie, in parous and nulliparous women; category 1) of induced abortion is to include a term in the calculation of the OR for the effect of age at first live birth or first full 
term pregnancy. Thirteen of the 21 studies in which an overall OR was reported (table 2, category 1) calculated the OR by multiple logistic regression. ${ }^{515354565963646769-71}$ Two studies which did not ${ }^{5768}$ reported that it made no difference, five ${ }^{115161852}$ studies only reported crude ORs, and one ${ }^{65}$ had insufficient data available on age at first full term pregnancy. Thus there are 15 studies for which the overall effect of induced abortion has been measured with the possible confounding effect of age at full term pregnancy in parous women accounted for. Recalculation of the pooled OR using only these studies slightly reduces the pooled OR (to 1.2), which is still significant (95\% CI 1.1,1.3).

The same is true for other potential confounding variables for which terms were generally included in the multivariate analyses namely, parity, age at menarche, oral contraceptive use, and some measure of socioeconomic status (usually, educational level). A few studies also adjusted for other factors suspected of influencing breast cancer risk, such as alcohol and fat consumption, although none of these studies reported any significant effects of these variables.

INDUCED ABORTION BEFORE VERSUS AFTER FIRST FULL TERM PREGNANCY

With regard to the question of induced abortion before versus after first full term pregnancy in parous women, (categories $2 \mathrm{~b}$ versus 3 ; table 3 ), the aggregate OR is slightly but not significantly higher for the former (1.5 versus 1.3 ). Since only six studies addressed both these questions $\mathrm{s}^{353565970}$ and reported adequate data for the meta-analysis, a firm conclusion cannot be drawn at this time. However, if further research verifies this trend, it would provide evidence that induced abortion specifically increases breast cancer risk both by amplification of previously transformed, potentially cancerous cells, and of the number of normal, but primitive, cells (much more numerous before first full term pregnancy) vulnerable to subsequent mutagenesis.

It is also noteworthy that four 5535970 of the six studies so far published reported higher ORs for induced abortion for before versus after first full term pregnancy, and the findings of the two which did not are explicable in terms consistent with the presently proposed mechanisms. Specifically, Daling et al ${ }^{\beta}$ also found no influence of age at first full term pregnancy as an independent risk factor. Thus, their finding of no added effect of abortion before versus after first full term pregnancy supports the concept that both of these types of exposure (ie, delayed first full term pregnancy and induced abortion before versus after first full term pregnancy) operate via the same mechanism (ie, by increasing the opportunity for primary carcinogenesis in normal but primitive cells). In contrast, Rosenberg et $a P^{56}$ found a higher OR for abortion after compared with before first full term pregnancy (table 2). However, this can be ascribed to the very large cohort effect in their study. Specifically, since the average patient was over age 40 while the average control was only about 30 when induced abortion was legalised in the US, the potential exposure of patients to induced abortion before first full term pregnancy was undoubtedly much lower than that of control subjects.

Unfortunately, the finding of no differential risk increase for abortion before compared with after the first full term pregnancy in one study ${ }^{3}$ has been interpreted as conflicting with previous animal data. Specifically, Daling et a ${ }^{\beta}$ refer to this finding in their own study as being, "not completely in accord with the results in experimental animals". Rosenberg ${ }^{4}$ called the same finding "a striking inconsistency with the model". Such conclusions are unwarranted, since the animal model to which these authors referred $^{2}$ did not include testing the effect of induced abortion after full term pregnancy. Rather, Russo and Russo ${ }^{2}$ compared breast cancer incidence in rats whose first pregnancy was aborted (via hysterectomy) before exposure to the chemical carcinogen, dimethylbenzanthracene, with that of rats who carried the pregnancy to term and to that of rats who never mated. The aborted group had a high mammary tumour incidence rate $(78 \%)$, as did the virgin rats $(71 \%)$ compared with the marked protective effect of carrying the first pregnancy to term ( $6 \%$ tumour incidence). Furthermore, histological examination of breast tissue from these animals revealed incomplete differentiation of primitive structures in the virgin and aborted rats, compared with those allowed to bear pups. While these findings provide excellent experimental evidence of the mechanism responsible for the protective effect of early first full term pregnancy (the abrogation of which is one way induced abortion increases breast cancer risk), this animal model system (wherein abortion precedes carcinogen exposure and wherein the effect of abortion on parous animals is not measured) does not fully address the question of the independent effect of induced abortion, which we largely ascribe to the oestradiol mediated promotion of the growth of previously transformed cells.

\section{EFFECT OF INDUCED VERSUS SPONTANEOUS} ABORTION

Whatever the details of the mechanism(s) by which induced abortion may independently increase the breast cancer risk, the fact that the first trimester of pregnancy is characterised by high levels of ovarian oestradiol makes this risk factor consistent with most others (eg, early menarche, late menopause, postmenopausal obesity), which are also associated with some form of oestrogen excess. However, the overall lack of association found with spontaneous abortion raises the important question of why any early termination of a pregnancy, whether natural or artificial, does not have the same effect. Various hypotheses have been offered to explain this apparent paradox, ranging from "the inherent difficulty in detecting" spontaneous abortion" ${ }^{5}$ to the possibility that "the relatively short gestational length" of spon- 
taneously aborted pregnancies might make them less likely to raise breast cancer risk. ${ }^{3}$ Lipworth et alP have even suggested that this discrepancy might provide a reason to dismiss the association of induced abortion and breast cancer altogether, as an artifact "generated by subtle information bias".

However, consideration of the endocrinology of normal compared with threatened early pregnancy provides a straightforward explanation: The first trimester of most pregnancies which end in miscarriage is characterised by subnormal oestradiol secretion. As early as 1976, Kunz and Keller ${ }^{83}$ found subnormal maternal oestradiol to be the most reliable predictor of first trimester miscarriage. In their 1990 study of 221 pregnancies, Witt et $a l^{\beta 4}$ observed that maternal oestradiol in women with apparently normal pregnancies of 11 weeks' gestation or less (from last menstrual period) averaged one third lower in pregnancies that ended in a first trimester miscarriage. More strikingly, they observed that in pregnant women with threatening symptoms (significant vaginal bleeding), oestradiol averaged only one sixth the average normal pregnancy level in pregnancies which went on to miscarry in the first trimester. ${ }^{84}$ Recently, Stewart et $a^{\beta 5}$ performed daily longitudinal hormone measurements on 24 normal women of proven fertility. They detected statistically significantly higher maternal oestradiol levels within six days after the luteinizing hormone peak in conceptive cycles $(n=14)$ that resulted in viable pregnancy. In contrast, conceptive cycles that ended in spontaneous abortion $(n=9)$ showed a subnormal oestradiol rise that did not significantly exceed non-conceptive levels until the 10th day after the peak, by which time oestradiol begins to decline in a non-pregnant cycle.

\section{EFFECT OF SINGLE VERSUS MULTIPLE INDUCED} ABORTIONS

Ten of the studies in the present meta-analysis present overall ORs for two or more induced abortions $^{1516525456596367-69}$. However, these 10 studies represent a subset in which the overall OR for one or more induced abortions is lower $(1.1 ; 95 \%$ CI: $1.0,1.3)$ than that obtained for all 21 studies providing this statistic $(1.3 ; 1.2$, 1.4 ; table 2 , category 1 ). Thus, the finding that the OR for two or more abortions is identical to that calculated for one or more $(1.1 ; 1.0$, 1.3) may not be representative. In fact, seven of the 10 studies reporting the multiple abortion OR report slightly (though not significantly) higher ORs for two or more, as opposed to one abortion..$^{15165254596869}$ The extant data are therefore insufficient to draw any firm conclusions about any overall dose effect of induced abortion at the present time.

A particularly important reason to refrain from dismissing the apparent lack of a dose effect of induced abortion is given in the study of Howe et $a l^{57}$ whose multiple abortion data set was excluded from the calculations above because it appears to describe only a special case of multiple abortion - ie, two consecutive induced abortions with no live birth intervening. Since this history pertained to 10 cases and no controls (out of 1451 matched pairs), the OR could not be calculated. If the principal mechanism of risk elevation by induced abortion is the oestrogenic growth promotion of existing abnormal cells or clones which would otherwise be eliminated (or at least inhibited) by the completion of the pregnancy, then one would predict a much greater dose effect if two (or more) artificially interrupted pregnancies followed consecutively. Thus, it would be particularly useful if the prospective data base used by Howe et $a l^{57}$ which has been growing since 1980 (when that study was terminated), were followed up to verify this trend.

\section{EFFECT OF GESTATIONAL AGE}

Most studies did not specify the gestational age of the fetus at the time of induced abortion, with the exception of the studies of Pike et al ${ }^{49}$ ( $<12$ weeks), Howe et $a P^{77}$ (20 weeks or less), Daling $e t a l^{\beta}$ and Rookus and van Leeuwen ${ }^{70}$ (1-8 weeks and 9-12 weeks, calculated separately). However, since the overwhelming majority of induced abortions occur in the first trimester, and almost all the rest in the second trimester (which would still be expected to increase risk, as reported by Daling et $a \mathcal{l}^{\beta}$ ), it is highly unlikely that the overall results reported would be materially affected by third trimester abortions. Indeed, Howe et $a P^{7}$ found that inclusion of third trimester abortions did not affect the results in their study. Of the two studies which divided the analysis according to early and late first trimester abortions, on $\mathrm{e}^{3}$ found the later abortions (9-12 weeks) to be associated with a slightly (but insignificantly) higher OR $(1.9 ; 95 \%$ CI $1.3,2.9)$ than the earlier abortions ( $1-8$ weeks: $\mathrm{OR}=1.4 ; 1.0$, $1.8)$, and the other study ${ }^{70}$ found the reverse ( $1-8$ weeks: $\mathrm{OR}=2.1 ; 1.1,4.2 ;>8$ weeks: $\mathrm{OR}=$ $1.6 ; 0.8,3.5)$. Thus, there is no reason to suspect that new technologies, (such as mifepristone/misoprostol) that would result in generally earlier terminations, would not also be associated with increased breast cancer risk.

\section{EFFECT OF AGE AT FIRST (OR ONLY) ABORTION} Two studies have examined this question, namely, those of Rosenberg et $a P^{6}$ and Daling et al. ${ }^{3}$ The former study only considered nulliparous women in this regard, and reported no significant differences in risk, with adjusted ORs ranging from 1.0 to 1.5 over the age range of under 20 years to 30 years and over. Daling et $a l^{\beta}$ also reported no significant differences, but they noted a trend toward increased risk in women with first induced abortion under 18 years old and over 29 years old, which they correlated with the histological data from the human biopsy study of Russo et al. ${ }^{82}$ In noting that the rate of cell proliferation is likely to be highest in the youngest subjects, Daling et $a l^{\beta}$ have prudently suggested that the greater elevation in risk for women under 18 at the time of 
their first (or only) abortion may be real and should be further investigated.

\section{IMPORTANCE OF AGE AT DIAGNOSIS}

Because the incidence of breast cancer in the western world rises with age throughout the lifespan ${ }^{86}$ (whereas in Japan, incidence levels off in the fifth decade and actually drops somewhat later $\mathrm{on}^{86}$ ), the range of ages at diagnosis in any epidemiological study is the most crucial determinant of the practical significance, in terms of excess cases expected, of the RR determined in the study. Many of the studies published thus far have been restricted to younger women - ie, under age $33,{ }^{49} 40,{ }^{57}$ $45,,^{35459869}$ or $57,{ }^{67}$ generally because only younger women would have been exposed to legalised abortion. As we have already discussed in the present report, most studies that include older women are not only weakened by the lack of exposure of the older women, but also by the cohort effect of having the controls younger than the patients, which tends artificially to lower the calculated ORs. In broad terms, even if the overall weighted pooled OR of $1.3( \pm 0.1)$ were to be applicable only to women up to age 50 , in whom the incidence of breast cancer is about $2 \%$, and this $30 \%$ odds increase were to be applied only to the approximately 800000 patients having their first induced abortion each year in the US, for example, the calculated excess incidence of breast cancer would be $4700( \pm 1600)$ cases per year in the US. As abortion has been legal in the US for up to a quarter century, an excess incidence of this magnitude should already be occurring. Since over 30000 cases are already diagnosed in women under age 50 each year, an excess incidence of 4700 might well escape our notice.

Yet, as significant a public health tragedy as this figure suggests, there is reason to believe that it may seriously underestimate the magnitude of the present and future problem. For example, the recent study of Rookus and van Leeuwen $^{70}$ reports a significant, overall OR in patients under age 55 diagnosed between 1986 and 1989 , of 1.9 , which is identical to that reported by Howe $e t a F^{7}$ for patients under age 40 a decade earlier. Another recent example is the study of Lipworth et al, ${ }^{5}$ which (although the age distribution of subjects was not given) had no age restriction and which reported an overall OR of 1.51 for women in Greece, where, according to the authors, "Even before their legalisation, induced abortions were practiced with widespread social acceptance". In the US, the recent study of Laing et $a l^{65}$ on AfricanAmerican women had no age restriction on patients, and $62 \%$ of those patients with a history of induced abortion were age 50 and over. The results are particularly troubling since the OR was found to increase with age, up to 4.7 in the 50 and over stratum. Newcomb et $a l^{1}$ reported a similar trend of increasing risk with age at diagnosis.

Thus, the available evidence so far suggests that the $30 \%( \pm 10 \%)$ increased risk calculated in the present meta-analysis will probably apply, at a minimum, to incidence rates at advanced ages, where such rates are much higher. At a currently estimated lifetime risk in US women of $12 \%$, the 800000 first abortions performed each year would thus generate 24500 ( \pm 7800$)$ excess cases each year, once the first cohort exposed to legal abortion reaches their ninth decade, in the fourth decade of the 21 st century. Furthermore, it is worthy of emphasis that even this forbidding figure does not reflect the nonspecific effect of induced abortion in delaying first full term pregnancy, which has been discussed in the present review, but was explicitly eliminated from the quantitative meta-analysis. This effect would apply variably to the approximately 800000 first abortion patients each year, and it could raise the estimate of excess breast cancer incidence which may be attributable to induced abortion considerably.

\section{EFFECTS OF INTERACTION WITH OTHER} VARIABLES

A few investigators have begun to explore the possible interaction of induced abortion with at least one risk factor other than age at first full term pregnancy, namely, family history. Thus, Parazzini et $a t^{t^{2}}$ found no interaction at all, although their numbers were small, and they also found, contrary to most other reports, no overall effect of reproductive risk factors in women with positive family history, reporting no "strong or significant effect of the best recognized factors for breast cancer risk, and several of the observed trends were in the opposite direction". Only two other studies addressed the interaction of family history and induced abortion. Andrieu et $a l^{67}$ calculated an OR of 7.1 for women with two or more induced abortions and a family history, but the number of subjects (nine patients and four controls) was very low. Daling et $a \beta^{\beta}$ found only a slightly higher OR for women with a positive first- or second degree family history (1.8 versus 1.5 overall), but they found much stronger associations when they also figured in the effect of age at first (or only) induced abortion. Thus, the OR went up to 3.7 for women whose first induced abortion was over age 30 (14 cases and 3 controls), and it was incalculable for women whose first abortion was under age 18 , since such family history and induced abortion history applied to 12 cases and no controls.

\section{Conclusions}

We believe that the present review and metaanalysis summarises a literature that documents a remarkably consistent, significant positive association between induced abortion and breast cancer incidence, independent of the effect an induced abortion has in delaying first full term pregnancy. Moreover, the increased risk is seen in both prospective and retrospective studies from around the world, in populations with the widest imaginable differences in ethnicity, diet, socioeconomic and lifestyle factors and social morays, and which also differ widely in size and in many aspects of design, and whose data extend over more than half a century in time. 
We are convinced that such a broad base of statistical agreement rules out any reasonable possibility that the association is the result of bias or any other confounding variable. Furthermore, this consistent statistical association is fully compatible with existing knowledge of human biology, oncology and reproductive endocrinology, and supported by a coherent (albeit incomplete) body of laboratory data as well as epidemiological data on other risk factors involving oestrogen excess, all of which together point to a plausible and likely mechanism by which the surging oestradiol of the first trimester of any normal pregnancy, if it is aborted, may add significantly to a woman's breast cancer risk.

Finally, it should be acknowledged that induced abortion is the most common elective surgical procedure currently performed in the US. While other elective, risk enhancing matters of choice, such as cigarette smoking, require thousands of exposures to produce detectable increases in cancer incidence, the induced abortion patient's risk of breast cancer later in life is measurably increased after a single exposure. Therefore, while the need for further research cannot be denied, especially given the existence of prospective data ${ }^{57}$ that can be studied with minimal cost, there exists the more present need for those in clinical practice to inform their patients fully about what is already known.

The authors wish to thank Alicia Fisher for running the computer analyses, and Cheryl Gates for her assistance in preparing the manuscript. This work was supported in part by a Legislative Initiative Grant, Contract no175169, from the Department of Education of the Commonwealth of Pennsylvania (JS-L), and
by a Fellowship Leave Award (JB) from Baruch College of the by a Fellowship Leave Award
City University of New York.

1 Segi M, Fukushima I, Fujisaku S, et al. An epidemiological study on cancer in Japan. GANN 1957;48(Suppl):1-63.

2 Russo J, Russo IH. Susceptibility of the mammary gland to carcinogenesis. Am f Pathol 1980;100:497-512.

3 Daling JR, Malone KE, Voigt LF, White E, Weiss NS. Risk of breast cancer among young women: relationship to induced abortion. $\mathcal{f}$ Natl Cancer Inst 1994;86:1584-92.

4 Rosenberg L. Induced abortion and breast cancer: more
scientific data are needed (editorial). $\mathcal{f}$ Natl Cancer Inst scientific data are
1994;86:1569-70.

5 Lipworth L, Katsouyanni K, Ekbom A, Michels KB, Trichopoulos $\mathrm{D}$. Abortion and the risk of breast cancer: a case-control study in Greece. Int $\mathcal{F}$ Cancer 1995;61:181-4.

6 Harris JR, Lippman ME, Veronesi U, Willett W. Breast cancer. (first of three parts). New Engl $\mathcal{f}$ Med 1992;327: 319-28.

7 Hulka BS, Stark AT. Breast cancer: cause and prevention. Lancet 1995;346:883-7.

8 Kvale G. Reproductive factors in breast cancer epidemiology. Acta Oncol 1992;31:187-94.

9 Michels KB, Hsieh C, Trichopoulos D, Willett W. Abortion and breast cancer risk in seven countries. Cancer Cause Control 1995;6:75-82.

10 Kelsey JL, Gammon MD, John EM. Reproductive factors and breast cancer. Epidemiol Rev 1993;15:36-47.

11 Harlap S. Oral contraceptives and breast cancer: cause and effect? F Reprod Med 1991;36:374-95.

12 Remennick LI. Induced abortion as cancer risk factor: a review of epidemiological evidence. $\mathcal{F}$ Epidemiol Community Health 1990;44:259-64

13 Hadjimichael OC, Boyle CA, Meigs JW. Abortion before first live birth and risk of breast cancer. Br f Cancer 1986;

14 Vessey MP, McPherson K, Yeates D, Doll R. Oral contraceptive use and abortion before first term pregnancy in relation to breast cancer risk. Br f Cancer 1982;45:327-31.

15 Watanabe H, Hirayama T. Epidemiology and clinical aspects of breast cancer. Nippon Rinsho 1968;26:1853-9 (in Japanese).

16 Nishiyama F. The epidemiology of breast cancer in Tokushima prefecture. Shikoku Ichi 1982;38:333-43 (in Jap-

17 Gandra L, Barros H, Moreira A, Calheiros F, Magalhaes N. Risk factors for breast cancer. Acta Med Portuguesa
Nondra L, Barros H, Moreira A, Calheiros F, Magalhaes 1993;6:129-33 (in Portuguese)

18 Dvoirin VV, Medvedev AB. Role of women's reproductive status in the development of breast cancer. In: Methods and progress in breast cancer epidemiology research, Tallin, 1978. Moscow: Oncology Science Center of the USSR Academy of Sciences, 1978;53-63 (in Russian).

19 Levshin VF, Chepurko AD. Reproductive history and breast cancer. Soviet Medicine 1986;6:15-21 (in Russian).

20 Wynder EL, Bross IJ, Hirayama T. A study of the epidemiology of cancer of the breast. Cancer 1960;13:559601

21 Stewart HL, Dunham LJ, Casper J, et al. Epidemiology of cancers of uterine cervix and corpus, breast and ovary in Israel and New York City. F Natl Cancer Inst 1966;37: $1-95$.

22 Valaoras VG, MacMahon B, Trichopoulos D, Polychronopoulou A. Lactation and reproductive histories of breast cancer patients in greater Athens, 1965-67. Int f Cancer 1969;4:350-63.

23 Salber EJ, Trichopoulos D, MacMahon B. Lactation and reproductive histories of breast cancer patients in Boston, reproductive histories of breast cancer patients

24 Lowe CR, MacMahon B. Breast cancer and reproductive history of women in South Wales. Lancet 1970;1(639): 153-7.

25 Yuasa S, MacMahon B. Lactation and reproductive histories of breast cancer patients in Tokyo, Japan. Bull World Health Organ 1970;42:195-204.

26 Mirra AP, Cole P, MacMahon B. Breast cancer in an area of high parity: Sao Paulo, Brazil. Cancer Res 1971;31 77-83.

27 Ravnihar B, MacMahon B, Lindtner J. Epidemiologic features of breast cancer in Slovenia, 1965-1967. Eur $\mathcal{f}$ tures of breast cancer $1971 ; 7: 295-306$.

28 Lin TM, Chen KP, MacMahon B. Epidemiologic characteristics of cancer of the breast in Taiwan. Cancer 1971; 27:1497-504.

29 Paymaster JC, Gangadharan P. Some observations on the epidemiology of cancer of the breast in women of western India. Int $\mathcal{F}$ Cancer 1972;10:443-50.

30 Stavraky K, Emmons S. Breast cancer in premenopausal and postmenopausal women. $\mathcal{F}$ Natl Cancer Inst 1974;53 647-54.

31 Abeatici S, Raso ANL Merlo G, Lepora P, Dorigo M, Mussa A. Computerized study of biological and environmental characteristics of patients with breast cancer. Minerva Med characteristics of patients with brea

32 Herity BA, O'Halloran MJ, Bourke GJ, Wilson-Davis K. A study of breast cancer in Irish women. Br 7 Prev Soc Med study of breast ca

33 Soini I. Risk factors of breast cancer in Finland. Int $\mathcal{F}$ Epidemiol 1977;6:365-73.

34 Choi NW, Howe GR, Miller AB, et al. An epidemiologic study of breast cancer. Am $\mathcal{F}$ Epidemiol 1978;107:510-21.

35 Toti A, Piffanelli A, Pavanelli T, et al. Possible indication of breast cancer risk through discriminant functions. Cancer 1980;46:1280-5.

36 Paffenbarger RS Jr, Kampert JB, Chang HG. Characteristics that predict risk of breast cancer before and after the menopause. Am $\mathcal{A}$ Epidemiol 1980;112:258-68.

37 Kelsey JL, Fischer DB, Holford TR, et al. Exogenous estrogens and other factors in the epidemiology of breast trogens and other factors in the epidemiology
cancer. $f$ Natl Cancer Inst 1981;67:327-33.

38 Lubin JH, Burns PE, Blot WJ, et al. Risk factors for breast cancer in women in northern Alberta, Canada, as related to age at diagnosis. $\mathcal{F}$ Natl Cancer Inst 1982;68:211-17.

39 Helmrich SP, Shapiro S, Rosenberg L, et al. Risk factors for breast cancer. Am $\mathcal{f}$ Epidemiol 1983;117:35-45.

40 Enachescu D, Lemneanu S. Associated mammary neoplasm risk factors considered by means of retrospective ep31.

41 Talamini R, La Vecchia C, Franceschi S, et al. Reproductive and hormonal factors and breast cancer in a northern and hormonal factors and breast cancer in a no

42 Kvale G, Heuch I, Eide GE. A prospective study of reproductive factors and breast cancer. Am $\mathcal{F}$ Epidemiol 1987; 126:831-41

43 Yuan J-M Yu MC, Ross RK, Gao Y-T, Henderson BE. Risk factors for breast cancer in Chinese women in Shanghai. Cancer Res 1988;48:1949-53.

44 Bernstein L, Pike MC, Krailo M, et al. Update of the Los Angeles study of oral contraceptives and breast cancer: 1981 and 1983. In: Mann RD, ed. Oral contraceptives and breast cancer. The implications of the present findings for breast cancer. The implications of the present findings for
informed consent and informed choice. Park Ridge, NJ: Paninformed consent and infor

45 Sellers TA, Potter JD, Severson RK, et al. Difficulty becoming pregnant and family history as interactive risk factors for postmenopausal breast cancer: the Iowa women's health study. Cancer Cause Control 1993;4:21-8.

46 Andrieu N, Clavel F, Auquier A, et al. Variations in the risk of breast cancer associated with a family history of breast cancer according to age at onset and reproductive factors. f Clin Epidemiol 1993;46:973-80.

47 Rao DN, Ganesh B, Desai PB. Role of reproductive factors in breast cancer in a low-risk area: a case-control study. $\mathrm{Br} \mathcal{F}$ Cancer 1994;70:129-32.

48 Andrieu N, Demenais F. Role of genetic and reproductive factors in breast cancer. Genet Epidemiol 1994;11:A285.

49 Pike MC, Henderson BE, Casagrande JT, Rosario I, Gray GE. Oral contraceptive use and early abortion as risk factors for breast cancer in young women. $\mathrm{Br} \mathcal{f} \mathrm{Cancer}$ factors for breast

50 Mantel N, Haenszel W. Statistical aspects of the analysis of data from retrospective studies of disease. $\mathcal{F}$ Natl Cancer Inst 1959;22:719-48. 
51 Hirohata T, Shigematsu T, Nomura AMY, Nomura Y, Horie A Hirota diet and reproductive history: A case-control study in diet and reproductive history: A case-control study in

52 Burany $\mathrm{C}$, Jan. Nall Cancer Inst cancer. Fugosl Ginekol Opstet 1979;19:237-47 (in SerboCroatian)

53 Brinton LA, Hoover R, Fraumeni JF Jr. Reproductive factors in the aetiology of breast cancer. Br $\mathcal{f}$ Cancer 1983;47: $757-62$.

54 Le M-G, Bachelot A, Doyon F, Kramar A, Hill C. Ora contraceptive use and breast or cervical cancer: Preliminary results of a French case-control study. In: Wolff $\mathrm{J}-\mathrm{P}$, Scott JS, eds. Hormones and sexual factors in human cancer aetiology. Amsterdam: Elsevier, 1984:139-47. 55 Ewertz $M$, Duffy $S W$. Risk of breast cancer in relation to
reproductive factors in Denmark. $B r f$ Cancer 1988;58: 99-104.

56 Rosenberg L, Palmer JR, Kaufman DW, Strom BL, Schottenfeld D, Shapiro S. Breast cancer in relation to the occurrence and time of induced and spontaneous abortion. Am 7 Epidemiol 1988;127:981-9.

57 Howe HL, Senie RT, Bzduch H, Herzfeld P. Early abortion and breast cancer risk among women under age 40 . Int $\mathcal{F}$ Epidemiol 1989;18:300-4.

58 Harris B-M L, Eklund G, Meirik O, Rutqvist LE, Wiklund $\mathrm{K}$. Risk of cancer of the breast after legal abortion during first trimester: a Swedish register study. $B M \mathcal{F} 1989 ; 299$ : $1430-2$.

59 Adami H-O, Bergstrom R, Lund E, Meirik O. Absence of association between reproductive variables and the risk of breast cancer in young women in Sweden and Norway. $B r \mathcal{F}$ Cancer 1990;62:122-6.

60 La Vecchia C, Decarli A, Parazzini F, et al. General epidemiology of breast cancer in northern Italy. Int $\mathcal{F}$ Epidemiol 1987;16:347-55

61 Parazzini F, La Vecchia C, Negri E. Spontaneous and induced abortions and risk of breast cancer. Int 7 Cancer 1991;48:816-20.

62 Parazzini F, La Vecchia C, Negri E, Franceschi S, Bocciolone L. Menstrual and reproductive factors and breast cancer in women with family history of the disease. Int $\mathcal{f}$ Cancer 1992;51:677-81.

63 La Vecchia C, Negri E, Franceschi S, Parazzini F. Longterm impact of reproductive factors on cancer risk. Int $\mathcal{F}$ Cancer 1993;53:215-9.

64 Moseson M, Koenig KL, Shore RE, Pasternack BS. The influence of medical conditions associated with hormones on the risk of breast cancer. Int 7 Epidemiol 1993;22. $1000-9$.

65 Laing AE, Demenais FM, Williams R, Kissling G, Chen VW, Bonney GE. Breast cancer risk factors in AfricanAmerican women: The Howard University Tumor ReAmerican women: The Howard University Tumor

66 Laing AE, Bonney GE, Adams-Campbell L, et al. Reproductive and lifestyle factors for breast cancer in Africanproductive and lifestyle factors for breast cancer in Af

67 Andrieu N, Clavel F, Gairard B, et al. Familial risk of breas cancer and abortion. Cancer Detect Prev 1994;18:51-5.
68 White E, Malone KE, Weiss NS, Daling JR. Breast cancer among young US women in relation to oral contraceptive use. F Natl Cancer Inst 1994;86:505-14.

69 Brinton LA, Daling JR, Liff JM, et al. Oral contraceptives and breast cancer risk among younger women. $\mathcal{f}$ Natl Cancer lnst 1995;87:827-35.

70 Rookus MA van Leeuwen FE. Breast cancer risk after. induced abortion, a Dutch case-control study. $A m \mathcal{F} E p$ idemiol 1995;141:S54 (abstract 214).

71 Newcomb PA, Storer BE, Longnecker MP, Mittendorf R, Greenberg ER, Willett WC Pregnancy termination in relation to risk of breast cancer. $\mathscr{f} A M A 1996 ; 275: 283-7$.

72 Schmid JE, Koch GG, La Vange LM. An overview of statistical issues and methods of meta-analysis. $\mathcal{F}$ Biopharm Stat 1991;1:103-20.

73 Shapiro S. Meta-analysis/schmeta-analysis. Am $\mathcal{F}$ Epidemiol 1995;140:771-8.

74 Petitti DB. Of babies and bathwater. Am 7 Epidemiol 1995; 140:779-82.

75 Greenland S. Can meta-analysis be salvaged? Am $\mathcal{F}$ Epidemiol 1995;140:783-7.

76 Shapiro S. Is there or ain't there no baby? Am $\mathcal{f}$ Epidemiol 1995;140:788-91.

77 Taubes G. Epidemiology faces its limits. Science 1995;269: $164-9$.

78 Gans JE, Coble YD, Estes EH Jr, et al (Council on Scientific Affairs), American Medical Association Council Report: Induced termination of pregnancy before and after Roe $\mathrm{v}$ Wade. $\mathcal{F} A M A$ 1992;268:3231-9.

79 Lindefors-Harris B-M, Eklund G, Adami H-O, Meirik O. Response bias in a case-control study: Analysis utilizing comparative data concerning legal abortions from two independent Swedish studies. Am $\mathcal{F}$ Epidemiol 1991;134: 1003-8.

80 Meirik O, Lund E, Adami H-O, Bergstrom R, Christoffersen $T$, Bergsjo P. Oral contraceptive use and breast cancer in young women. Lancet 1986;ii:650-4.

81 MacMahon B, Cole P, Lin TK et al. Age at first birth and breast cancer risk. Bull World Health Organ 1970;43: 209-21.

82 Russo J, Rivera R, Russo IH. Influence of age and parity on the development of the human breast. Breast Cancer Res Treat 1992;23:211-18.

83 Kunz J, Keller PJ. HCG, HPL, oestradiol, progesterone and AFP in serum in patients with threatened abortion. Br ₹ Obstet Gynaecol 1976;83:640-4.

84 Witt BR, Wolf GC, Wainwright CJ, Johnston PD, Thorneycroft IH. Relaxin, CA-125, progesterone, estradiol, Schwangerschaft protein, and human chorionic gonadotropin as predictors of outcome in threatened and nontropin as predictors of outcome in threatened and no

85 Stewart DR, Overstreet JW, Nakajima ST, Lasley BL. Enhanced ovarian steroid secretion before implantation in early human pregnancy. $\mathcal{F}$ Clin Endocrinol Metab 1993;76: early huma $1470-6$.

86 Thomas DB. Epidemiologic and related studies of breast cancer etiology. In: Lilienfeld AM, ed. Reviews in cancer epidemiology. New York: Elsevier-North Holland, 1980: 154-217. 